\title{
DIRECT WATER HEATER POWER CONTROL FOR REDUCED HARMONICS AND FLICKER CONTENT WITH OPTIMIZED HALF-CYCLE POWER CONTROL
}

\author{
Wilson Komatsu*, Cláudio José de Oliveira Júnior*, Paulo Sérgio Valle Carvalho* \\ "Escola Politécnica da Universidade de São Paulo *DEPD - Lorenzetti S/A \\ \#Av. Prof. Luciano Gualberto, trav. 3, no. 158, sala A2-05 - 05508-900 São Paulo SP BRAZIL \\ wilsonk@usp.br
}

\begin{abstract}
This paper presents an optimized Half-Cycle Power Control for Direct Water Heater with reduced harmonic content and flicker control. The method is presented, as well as results of theoretical analysis supported by experimental results.
\end{abstract}

Keywords - Cycle-by-cycle power control, direct water heater, flicker, half-cycle power control, harmonics and power quality, integral-cycle power control.

\section{INTRODUCTION}

Electronic power control of a Direct Water Heater (DWH) [1] is usually made by variation of the rms voltage applied to the resistive load. The more widespread used electronic power control for this application nowadays is the phase angle power control (PAPC) type [2], which changes the rms voltage content applied to load by shaping the sine current waveform through a semiconductor switch (e.g., a triac), between the voltage source and the controlled load. It is widely known that this type of power control produces highly distorted currents and its associated high harmonic content. Among the problems produced by harmonic distortion, one can mention [3][4][5]:

1. Reduction of transformers lifetime and motor operation malfunction;

2. Increased loss in conductors;

3. Electromagnetic interference in communication networks;

4. Erroneous breaker operation;

5. Excessive current in neutral conductors;

6. Power factor worsening due to harmonic rms current.

Besides, this type of control causes problems of voltage notching in the public supply network waveform [15].

This paper proposes an Optimized Half-Cycle Power Control (OHCPC) to minimize such problems, as well as flicker problems associated with PAPC and cycle-by-cycle power control (CBCPC), also known as integral-cycle power control. The OHCPC concept is primarily aimed for the control of a DWH as a household appliance, and is protected in Brazil by INPI process number PI-0103054-0 [16].

\section{CONVENTIONAL CYCLE-BY-CYCLE CONTROL}

The conventional CBCPC [6] is a better alternative, compared to PAPC, in DHW applications.

Manuscript received on May 11, 2006. First revision on August 14, 2006. Recommended by the Editors of the Special Section J. A. Pomilio and Andres Ortiz Salazar.
For " $m$ " cycles applied to load during the time " $T_{1}$ ", and being " $M$ " the number of cycles during the total time " $T$ ", the total power $P_{1}$ applied to the load is given by (1), being $P$ the total power if $m=M$ (see figure 1).

$$
P_{1}=P \cdot \frac{m}{M}
$$

The ratio " $m / M$ " given by (1) depends on the available controller precision.

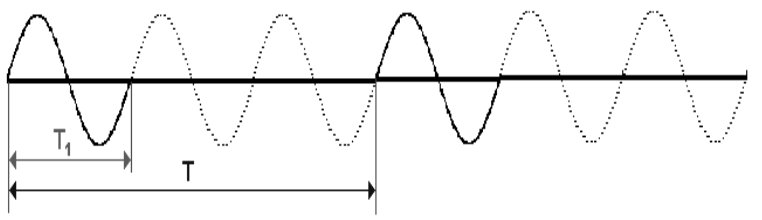

Fig. 1. Cycle-by-cycle (integral-cycle) power control.

The CBCPC removes harmonic distortion (for harmonic orders above the fundamental) and does not alter the power factor (compared to phase angle control), but some factors must be taken into consideration [7][8]:

1. Water temperature variation: In DWH, the power variation between on and off cycles can cause uncomfortable variation in output water temperature because there is little time of contact between the water and the heater element; if the rate of water flow is larger, the problem worsens;

2. DC current imbalance: One needs to ensure conduction for equal numbers of whole positive and negative halfcycles to avoid dc imbalances that can induce power-line distortion;

3. Flicker effect: The CBCPC, being a periodic sequence of on and off states, produces a sub-harmonic current. Depending on this sub-harmonic amplitude and frequency, light intensity oscillation in the lamps can be produced (flicker effect).

\section{THE FLICKER EFFECT}

Flicker [4][5][9][10][11][12][13][14] can be defined as the slow and repetitive variation of the rms value of voltage, typically at the 1 to 30 variations per second, being a negative factor as it induces an impression of unsteadiness on visual sensation, which is induced by a light stimulus whose luminance or spectral distribution fluctuates with time. It causes electrical and health problems, being the health problems usually more relevant.

Flicker (scintillation) curves, like the one shown in figure 2 , are empiric (produced from controlled practical experiences) and are usually given for rectangular voltage fluctuations in the frequency dominium. Above the curves, 
the probability of discomfort is larger, and under it is very small. As it is dependant on the time constant of the lamp, it is a function of the lamp power.

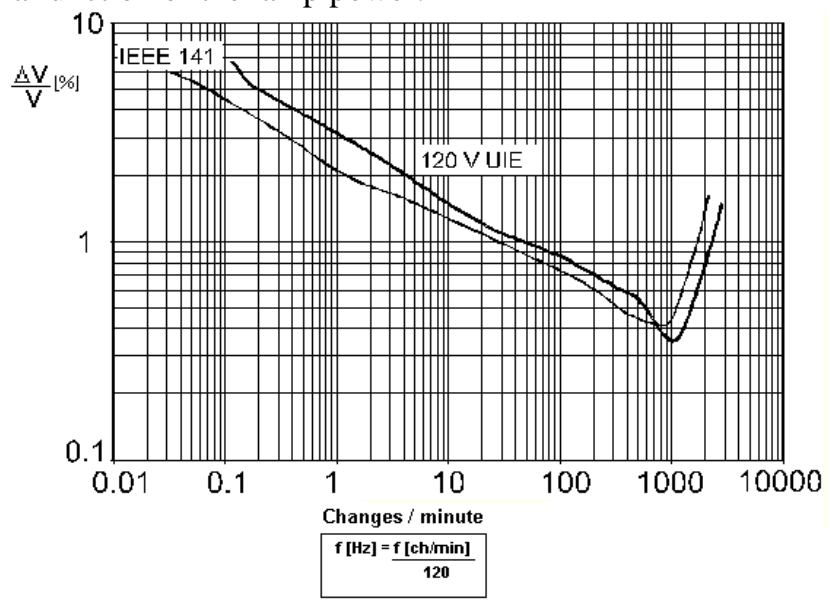

Fig. 2. Example of a typical flicker curve [12][13][14].

\section{A. The Human eye}

The persistence of the vision is the most important part under the point of view of the flicker effect. It consists on the retina property of keeping for some time (about $100 \mathrm{~ms}$ ) the image of any object. An incandescent lamp turns on and off at each $8,33 \mathrm{~ms}$ in $60 \mathrm{~Hz}$ (120 scintillations per second) so one does not perceive this oscillation. If this variation period is increased to a time period greater than 100 ms (less than 10 scintillations per second), one easily perceives the luminosity variation. As the iris is adjusted according to the variation of luminosity, it is greatly affected by low frequency scintillation.

\section{OPTIMIZED HALF-CYCLE POWER CONTROL}

A solution to minimize flicker effect is to apply an optimized half-cycle power control (OHCPC) [7][16]. For instance, given a total period $T$ of 3 AC cycles (1/20 seconds at $60 \mathrm{~Hz}$ ), the commutation must be done providing more than 30 changes for second, and keeping the DC level to zero. Such control configuration generates current waveforms as given in figures 3 and 4 .

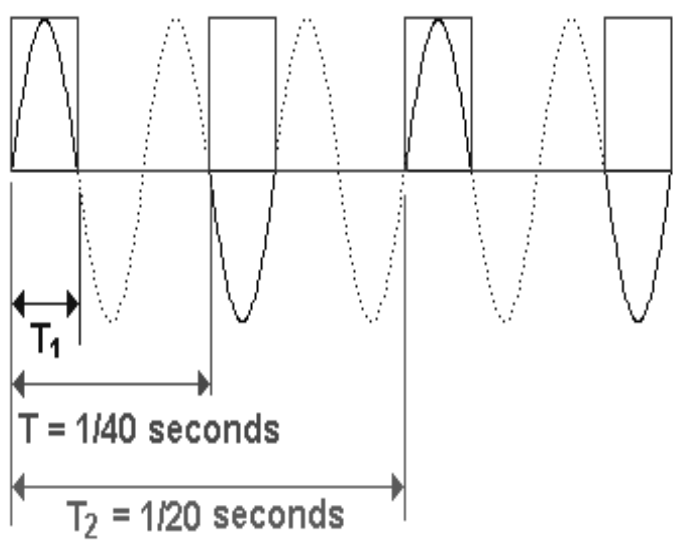

Fig. 3. Current waveform (not in scale) for OHCPC, providing 1/3 of total available electric power. $60 \mathrm{~Hz}$ mains frequency.

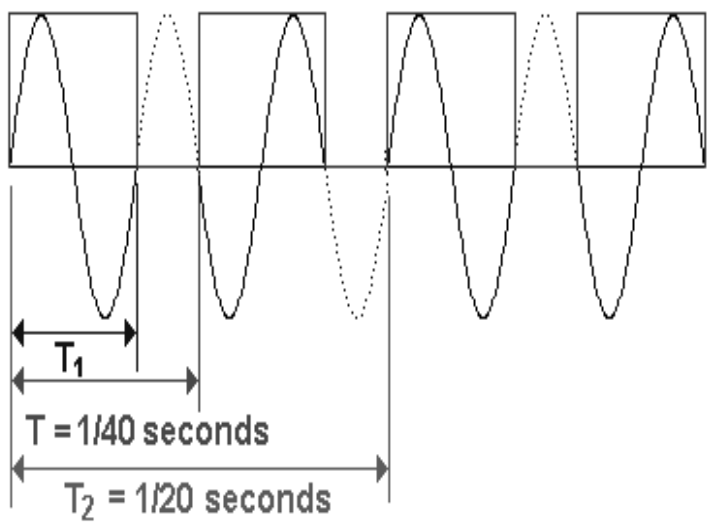

Fig. 4. Current waveform (not in scale) for OHCPC, providing 2/3 of total available electric power. $60 \mathrm{~Hz}$ mains frequency.

Some OHCPC features, at $60 \mathrm{~Hz}$ mains frequency, are:

1. Minimization and elimination of harmonics over $60 \mathrm{~Hz}$;

2. Flicker goes to 40 changes (scintillations) per second (4.800 changes/minute), above the human eye comfort limit, according to the flicker curve (figure 2);

3. Four temperature steps are possible with one heating element: null current (zero power), 1/3 of total power (figure 3 case), 2/3 of total power (figure 4 case) and the full waveform (full power);

4. On/off periods are reduced compared to CBCPC, which is suitable for DWH applications, as water temperature variation is minimized, thus improving user comfort.

The typical load for the application of this control type is one-phase fed, therefore maintaining power feeding compatibility with conventional DWHs. Three-phase loads were not studied, but there are no technical reasons forbidding such implementation.

\section{A. Power steps increase with more than one heater element}

Implementation of more than one independently controlled heating element (HE) allows more power steps, and if these HEs have different power rating, the power gradation can be smoother. For instance, by using two HEs with a power ratio of two (power $P$ for HE1 and $2 P$ for HE2), one can obtain 10 power steps: Element HE1 can deliver four power steps: zero, $P / 3,2 P / 3$ and $P$ (refer to waveforms of figures 2, 3). HE2 will have zero, $2 P / 3,4 P / 3$ and $2 P$ steps. This association can provide 10 power steps, as seen in Table I.

TABLE I

Available Power Steps associating two HEs, with total powers $P$ and $2 P$.

\begin{tabular}{cccccc}
\hline $\begin{array}{c}\text { HE1 } \\
\text { Step }\end{array}$ & $\begin{array}{c}\text { HE1 } \\
\text { power }\end{array}$ & $\begin{array}{c}\text { HE2 } \\
\text { Step }\end{array}$ & $\begin{array}{c}\text { HE2 } \\
\text { power }\end{array}$ & $\begin{array}{c}\text { Total Step } \\
\text { Number }\end{array}$ & $\begin{array}{c}\text { Total } \\
\text { Power }\end{array}$ \\
\hline 1 & 0 & 1 & 0 & 1 & 0 \\
\hline 2 & $\mathrm{P} / 3$ & 1 & 0 & 2 & $\mathrm{P} / 3$ \\
\hline 3 & $2 \mathrm{P} / 3$ & 1 & 0 & 3 & $2 \mathrm{P} / 3$ \\
\hline 4 & $\mathrm{P}$ & 1 & 0 & 4 & $\mathrm{P}$ \\
\hline 3 & $2 \mathrm{P} / 3$ & 2 & $2 \mathrm{P} / 3$ & 5 & $4 \mathrm{P} / 3$ \\
\hline 4 & $\mathrm{P}$ & 2 & $2 \mathrm{P} / 3$ & 6 & $5 \mathrm{P} / 3$ \\
\hline 3 & $2 \mathrm{P} / 3$ & 3 & $4 \mathrm{P} / 3$ & 7 & $2 \mathrm{P}$ \\
\hline 4 & $\mathrm{P}$ & 3 & $4 \mathrm{P} / 3$ & 8 & $7 \mathrm{P} / 3$ \\
\hline 3 & $2 \mathrm{P} / 3$ & 4 & $2 \mathrm{P}$ & 9 & $8 \mathrm{P} / 3$ \\
\hline 4 & $\mathrm{P}$ & 4 & $2 \mathrm{P}$ & 10 & $3 \mathrm{P}$ \\
\hline
\end{tabular}


Table I shows that with one HE there are four possible power steps. The increase of HEs allows for more power steps (equations 2 and 3):

$$
\begin{gathered}
N s=\frac{P T}{(m p / 3)}+1 \quad \rightarrow \quad N s=\frac{3 \cdot P T}{m p}+1 \\
N s=\left\lfloor\left(2^{N e}-1\right) \cdot 3\right\rfloor+1
\end{gathered}
$$

Ns $\rightarrow$ number of steps;

$P T \rightarrow$ total power of all HEs [W];

$m p \rightarrow$ power of the smallest HE [W];

$\mathrm{Ne} \rightarrow$ number of HEs;

Formulae (2) and (3) are valid only if all HEs powers are integer multiples of the smallest power (mp) HE. For instance:

0 in a DWH with two HEs, $P T=3 m p$;

0 in a DWH with three HEs, one can have $P_{H E 1}=m p=1.5 \mathrm{~kW}, P_{H E 2}=3 \mathrm{~kW}$ and $P_{H E 3}=6 \mathrm{~kW}$, resulting in $P T=7 \mathrm{mp}$.

Following the above requirement, Table II summarizes the relationship between power steps and number of heater elements.

TABLE II

Number of power steps $x$ number of heating elements.

\begin{tabular}{cc}
\hline Number of heating elements [Ne] & Number of steps [Ns] \\
\hline 1 & 4 \\
\hline 2 & 10 \\
\hline 3 & 22 \\
\hline 4 & 46 \\
\hline 5 & 94 \\
\hline 6 & 190 \\
\hline 7 & 382 \\
\hline 8 & 766 \\
\hline
\end{tabular}

A microcontroller allows the practical implementation of the OHCPC rules. In a balance between performance, cost and ease of implementation, $\mathrm{Ne}=2$ is usually applied.

\section{IMPLEMENTATION (FOR NE=2)}

\section{A. Hardware block diagram}

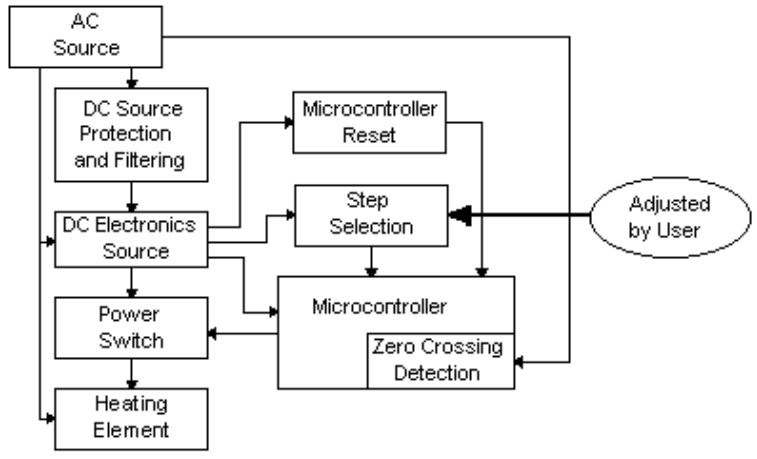

Fig. 5. Hardware block diagram.

The implemented hardware is presented in a block diagram form in figure 5. AC Source (mains) feeds the system. The DC Source Protection and Filtering block protects the DC Electronic Source, which provides reduced DC voltage for the control system. The Microcontroller
Reset resets the Microcontroller in the case of some abrupt AC variation voltage. The Step Selection block is a potentiometer commanded by the user and informs the desired heating level. The Microcontroller sends trigger order to the Power Switch block, which is composed by electronic switch(es) (triacs), connected to the HE(s). Zero Crossing indicator detects the AC voltage zero crossing instant, and is located inside the Microcontroller. In the proposed application environment (DWH control as a household appliance) this zero crossing detection method works flawlessly.

\section{B. Microcontroller pinout assignment description}

The applied microcontroller is Microchip PIC12C508A [17], with the pinout assignment shown in figure 6:

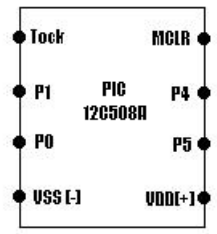

Fig. 6. Microchip PIC12C508A pinout.

$V S S(-)$ and $V D D(+)$ feed the IC; Tock receives attenuated AC signal for voltage zero crossing detection; $P 1$ and $P 0$ are analog or digital input gates, used to determine the number of steps Ns (equations (2), (3)) according to the received signal; MCLR resets the microcontroller if an abrupt AC voltage variation occurs; $P 4$ and $P 5$ are digital output gates that send trigger signals to the power switches (triacs).

C. Software Flowchart

Implemented software flowchart is illustrated in figure 7.

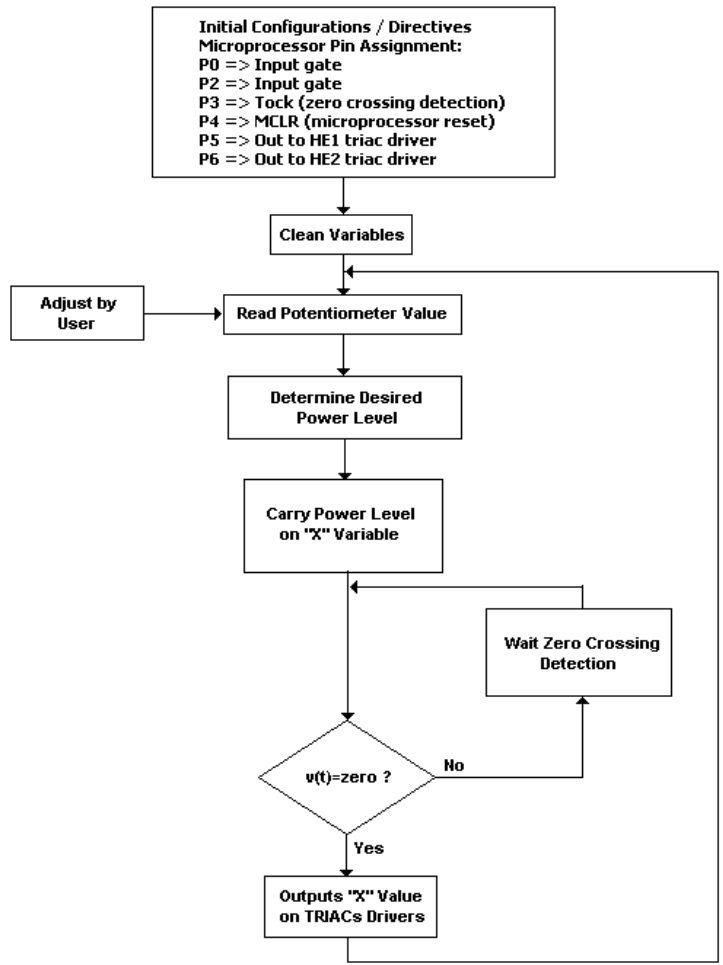

Fig. 7. Implemented software flowchart for two heating elements HE1 and HE2. 
" $X$ " variable in figure 7 indicates if the power switches (triacs) connected to HE 1 and HE2 are to be fired at the zero voltage crossing in each half cycle, according to the computed power level, following the strategy given in Table I.

\section{Hardware connection diagram}

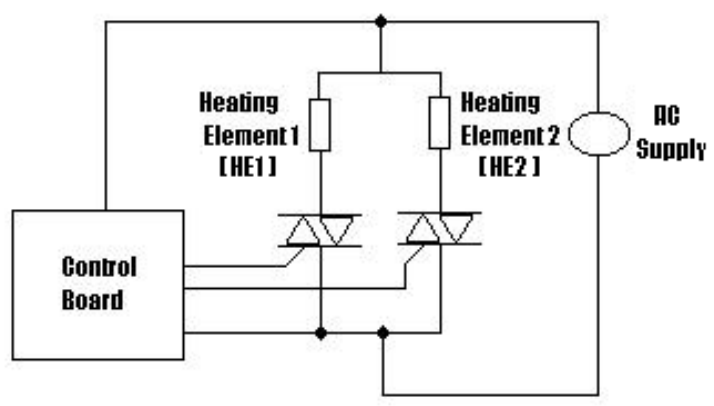

Fig. 8. Hardware connection diagram with two HEs $(\mathrm{Ne}=2)$.

Figure 8 shows a typical hardware connection diagram with two HEs $(\mathrm{Ne}=2)$.

\section{EXPERIMENTAL RESULTS}

\section{A. Hardware assembly}

The DWH Lorenzetti Jet Master model (7500W full power at 220V) was employed to obtain experimental measurements. Hardware assembly (figure 9) using only one HE was applied. The adopted power switch is the BTA41400B (400V, 40A) triac from STMicroelectronics (www.st.com).

In order to simulate a typical installation, the DWH was installed at the end of a $30 \mathrm{~m}$ long $6 \mathrm{~mm}^{2}$ cooper cable connected to the distribution box of the laboratory ${ }^{2}$. The voltage drop of the cable allows a realistic measurement of the flicker effect produced by the setup. An incandescent lamp (220V-60W) was put in parallel with the DWH, allowing a visual assessment of any visible flicker effect.

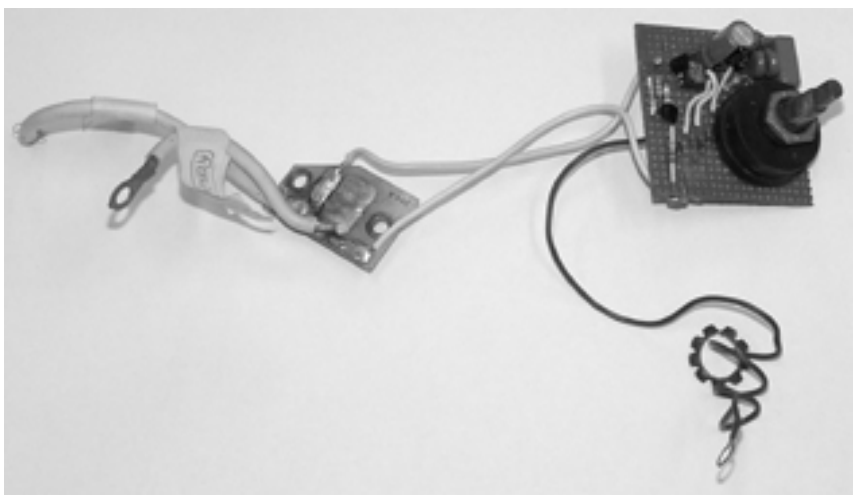

Fig. 9. Electronic circuit (triac assembly at the right, control board at the left) used in the experimental measurements. DWH, including its $\mathrm{HE}$, is not seen in this figure.

\footnotetext{
${ }^{2}$ These cable gauge and distance are practical recommendations of DWH makers, based on typical distances found in DWH installations following electrical installation standards (Brazilian NBR-5410).
}

\section{B. Measurements of AC waveforms and spectra}

OHCPC control laws corresponding to figures 3 and 4 (1/3 and 2/3 of total available power) were set and measured. AC voltage and current waveforms are shown in figures 10 and 12. Current spectra (figures 11 and 13) were obtained with FFT (Fast Fourier Transform) from the oscilloscope Tektronix model TDS3014B, with rectangular window.

Voltage drop at AC mains due to the currents generated by the OHCPC are in phase, because HEs are resistive loads.

RMS voltage value of mains changes according to graphics shown in figures 14 and 15 . With $1 / 3$ of available power (figures 10 and 11), RMS value keeps two half cycles at "high" level and one cycle at "low" level, repeating this sequence periodically. With $2 / 3$ of available power (figures 12 and 13) the sequence is one half cycle "high" and two "low", also periodically.

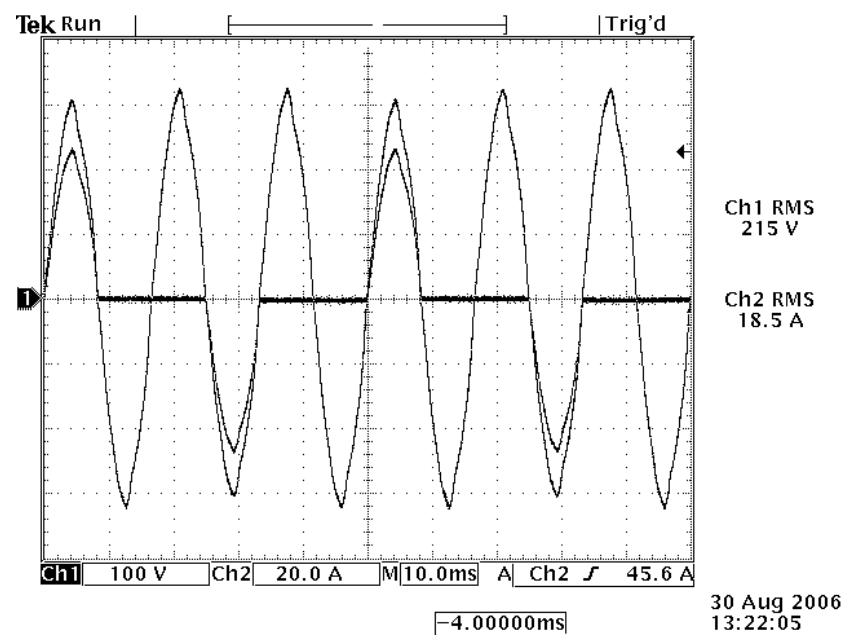

Fig. 10. Measured voltage and current waveforms for $1 / 3$ of available power.

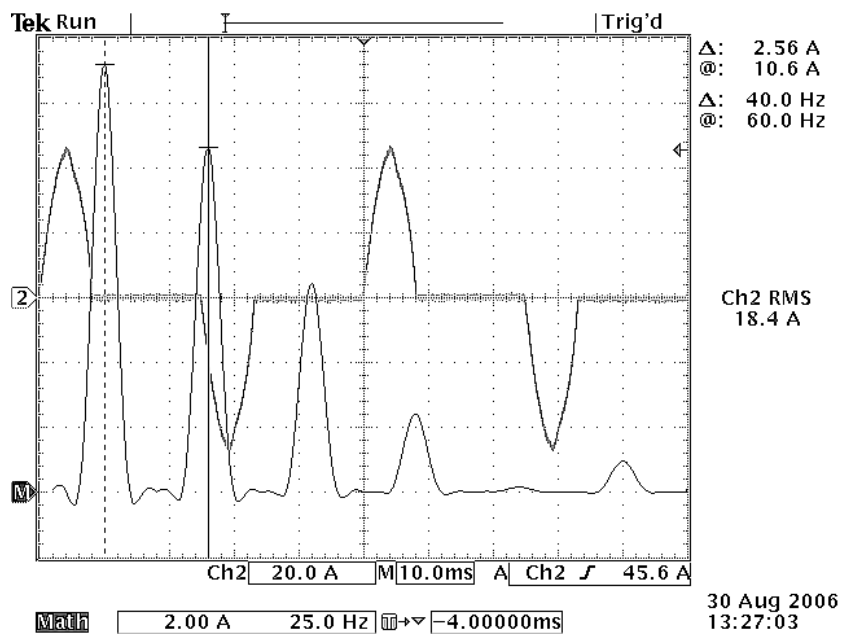

Fig. 11. Measured AC current spectrum for $1 / 3$ of available power. The "fundamental" (first) harmonic line in this spectrum is $20 \mathrm{~Hz}$ (a third of fundamental). The "third" harmonic line is, in this case, the mains frequency of $60 \mathrm{~Hz}$. Spectrum harmonic lines amplitudes are given here in rms values. 


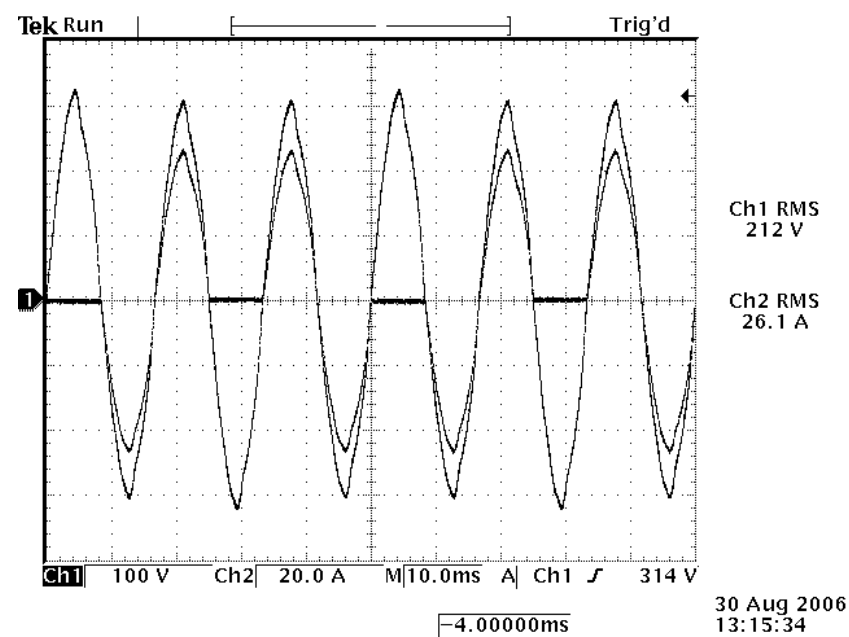

Fig. 12. Measured current waveform for $2 / 3$ of available power.

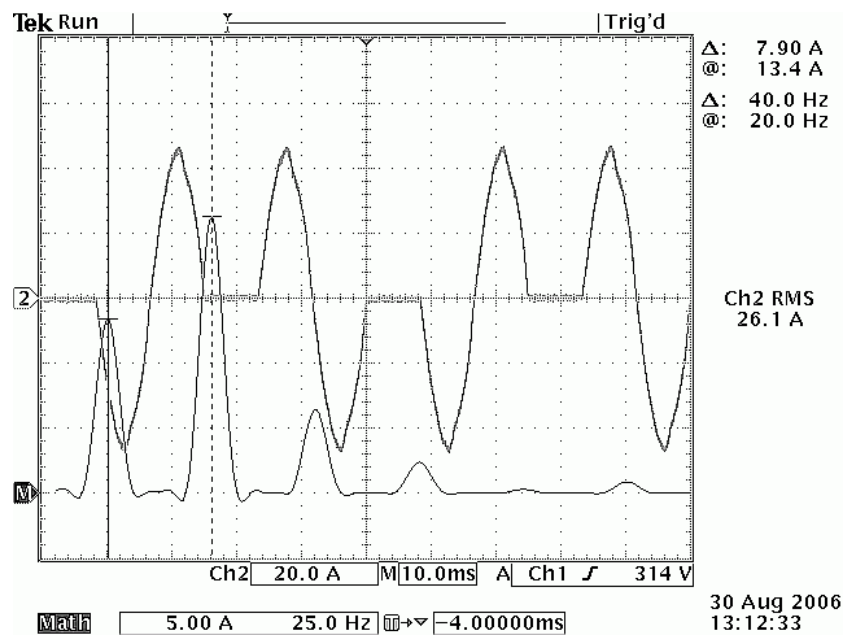

Fig. 13. Measured AC current spectrum for $2 / 3$ of available power. The "fundamental" (first) harmonic line in this spectrum is $20 \mathrm{~Hz}$ (a third of fundamental). The "third" harmonic line is, in this case, the frequency of $60 \mathrm{~Hz}$, and is lower than the $40 \mathrm{~Hz}$ ("second") line. Spectrum harmonic lines amplitudes are given here in rms values.

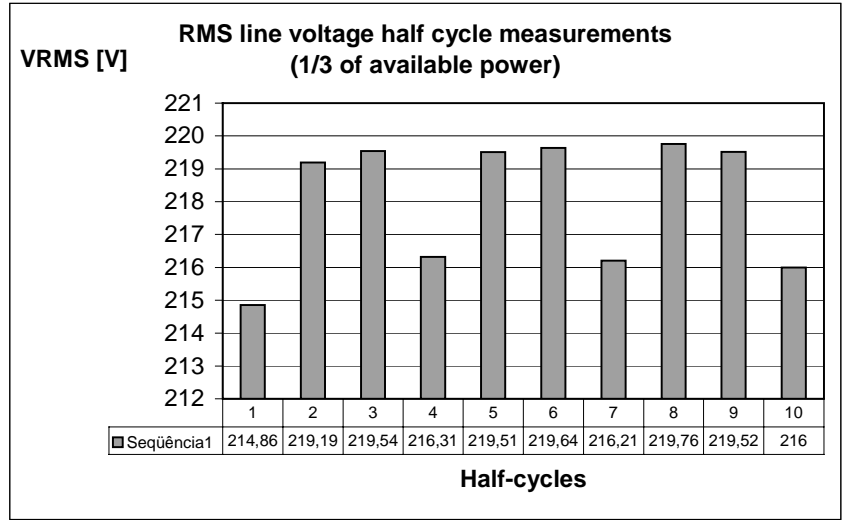

Fig. 14. Line RMS voltage variation, measured each half cycle, for $1 / 3$ of available power.

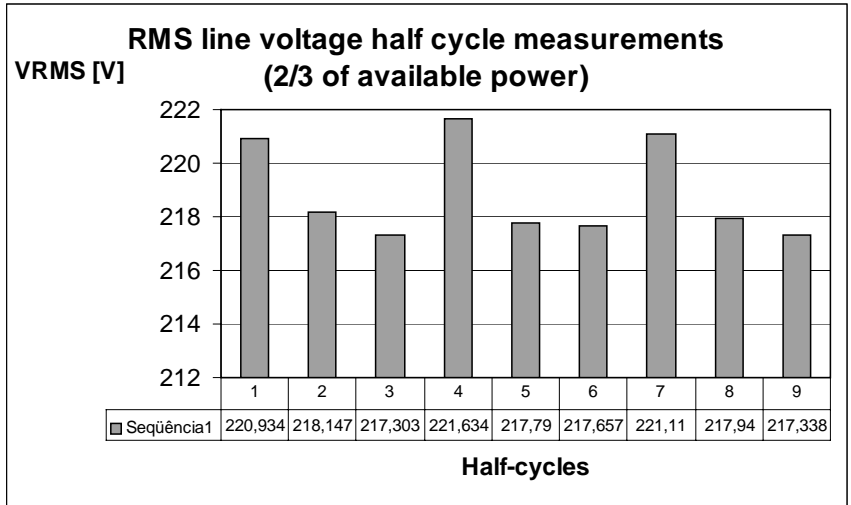

Fig. 15. Line RMS voltage variation, measured each half cycle, for $2 / 3$ of available power.

\section{Flicker measurements and analysis}

The direct measurement of flicker can be done with a flickermeter, according to Standard IEC-61000-3-3 [10]. The flickermeter RMS model MARH-VF (www.rms.com.br) was employed. For the $1 / 3$ and $2 / 3$ power settings, 10 measurements of $\mathrm{PST}^{3}$ were made, after system stabilization, in order to obtain averaged values. Measured values were:

- $\quad \mathrm{PST}=1.02 \pm 0.08$ (for $1 / 3$ power setting)

- $\mathrm{PST}=1.06 \pm 0.06$ (for $2 / 3$ power setting)

PST levels in low voltage systems should be lower than 1.0 (one point zero), based on a 95\% probability [13]. The flickermeter was placed in parallel with the DWH, in order to obtain the worst case measurement scenario. As the DWH circuit branch is independent from the other circuits in a given electrical installation, one can conclude that any other load in the installation will be submitted to lower levels of voltage variation provoked by the DWH switching pattern. Visual inspection of the 220V-60W incandescent lamp (in parallel with the DWH) also did not show perceptible flicker in both power levels (1/3 and 2/3 of total power).

As the mains frequency is $60 \mathrm{~Hz}$, each half-cycle has $1 / 120$ $\mathrm{s}$, thus three half-cycles have $3 / 120 \mathrm{~s}=25 \mathrm{~ms}$, meaning that each 25 ms the RMS value of the mains voltage changes twice (as one looks at the transition sequence "high" to "low" to "high"). It is equivalent to 80 changes/second, or 4,800 changes/minute.

Standard IEC-61000-3-3:1994+A1:2001 [10] define at item 3.5 voltage fluctuation as "series of changes of r.m.s. voltage evaluated as a single value for each successive halfperiod between zero-crossings of the source voltage", meaning that one has to "measure" (calculate) the rms value of voltage in each semi-cycle. As the rms value of a positive semi-cycle is the same as its negative counterpart [2], current waveforms of figures 10 and 12 have fundamental frequencies of $40 \mathrm{~Hz}$ (4,800 changes/minute), for flicker measurement effects.

Note 3 of item 4.2.3.2 of the same Standard (IEC-610003-3:1994+A1:2001 [10]) informs that no graphical extrapolation can be made on Standard curves in order to avoid unacceptable errors (original text: "Note 3:

\footnotetext{
${ }^{3}$ PST is a measure of short-term perception of flicker obtained for a tenminute interval. This value is the standard output of the IEC flickermeter [13]
} 
Extrapolation outside the range of the figures may lead to unacceptable errors". It means that, as figure 2 curves extend up to 3,000 changes/minute, and the OHCPC has 4,800 changes/minute, which is above the established upper limit of the curves, one can conclude that the OHCPC is in accordance of the limits established by Standard IEC-610003-3:1994+A1:2001 [10][12]. Also, studies demonstrate that the threshold of human irritability is around $30 \mathrm{~Hz}(3,600$ changes / minute) [5].

\section{FINAL REMARKS}

This paper proposes a power control, based on a modified cycle-by-cycle method, for direct water heaters, which minimizes current harmonics and flicker, usually associated with conventional power control schemes. The method is suitable to household direct water heaters, as it minimizes water temperature variations, improving user comfort. Theoretical analysis, supported by experimental results, validates the proposed method.

\section{ACKNOWLEDGEMENT}

The authors thank Lorenzetti S.A. and Expertise Engenharia Ltda for supporting this work.

\section{REFERENCES}

[1] Inmetro. Projeto de Norma de Chuveiros Elétricos Requisitos de desempenho e segurança de aparelhos eletrodomésticos fixos de aquecimento instantâneo de água; Inmetro; Revisão 04; 2001. <in Portuguese>

[2] M.H. Rashid. Power Electronics: Circuits, Devices and Applications. Prentice Hall, $2^{\text {nd }}$ Edition, 1993.

[3] Procobre. Qualidade de Energia - Harmônicas; Procobre - Instituto Brasileiro do Cobre. <pamphlet>

[4] J. Arrilaga, A. Bradley, P.S. Bodger. Power System Harmonics. John Wiley \& Sons, 1989.

[5] S.M. Deckmann. IT-012: Avaliação da Qualidade de Energia Elétrica. Unicamp, 2002. <class notes>.

[6] B.M. Bird, K.G. King, D.A.G. Pedder. An Introduction to Power Electronics, John Wiley \& Sons, $2^{\text {nd }}$ Edition, 1993.

[7] Lorenzetti. Estudos sobre Redução de Harmônicas. $<$ internal report>.

[8] Lorenzetti. Ensaios de Laboratório: Curvas de Pressão x Vazão, Temperatura x Vazão. <internal report>.

[9] IEC-61000-3-2. Edition 2.1; 2001.

[10] IEC-61000-3-3. Edition 1.1; 2002.

[11] IEC-61000-3-4. Première édition; 1998.

[12] IEC-61000-3-5. Première édition, 1998.

[13] IEEE Std 1453-2004. IEEE Recommended Practice for Measurement and Limits of Voltage Fluctuations and Associated Light Flicker on AC Power Systems. 2005.

[14] S.M. Halpin, R. Bergeron, T.M. Blooming, R.F. Burch, L.E. Conrad, T.S. Key. "Voltage and lamp flicker issues: should the IEEE adopt the IEC approach?” IEEE Transactions On Power Delivery, vol.18, n.3, pp.10881097, July 2003.

[15] N.C. Jesus, F.T. Castoldi, C.F.B. Nonenmacher, T.F. Santos, H.R.P.M. Oliveira, G. Papaléo. “Análise da
Influência de Cargas Não-Lineares: Avaliação dos Efeitos e Limites de Cortes de Tensão (Voltage Notching)“. In: Seminário Brasileiro sobre Qualidade da Energia Elétrica - SBQEE, 5. Sergipe, Aug. 2003. <in Portuguese>

[16] C.L. Lorenzetti. "Circuito Eliminador de Harmônicas e Flicker em Aquecedores Elétricos de Passagem”. Int. CI H02J-3/01 H05B-1/02 G05B-9/02 BR n. PI0103054-0. July, 2001. Revista da Propriedade Industrial: Seção I. Rio de Janeiro, n.1699, July 2003. <in Portuguese>

[17] PIC - 12C5XX - Series User's Manual - Microchip 2002

\section{BIOGRAPHIES}

Wilson Komatsu was born in São Paulo, Brazil, in 1963. He received his B.Sc. degree (electrical engineering) from the Polytechnic School of the University of Sao Paulo (EPUSP), Sao Paulo, Brazil, in 1986. In the same institution he obtained his M.Sc. and Ph.D. degrees in 1992 and 2000 respectively.

He worked at FDTE/EPUSP from 1987 to 1989 developing induction furnaces. In 1989 he became lecturer at EPUSP, teaching courses related to power electronics and control systems. Among his areas of interest are: quality of power, modeling of control systems and static converters as well as their application to electrical power systems.

Dr. Komatsu is a member of SOBRAEP and IEEE.

Cláudio José de Oliveira Júnior was born in Sao Paulo, Brazil, in 1974. He received his B.Sc. degree (electrical engineering) from Mauá Engineering School, São Caetano do Sul, Brazil, in 2002, and his B.Sc. degree (mathematics) from Osvaldo Cruz University, Sao Paulo, Brazil, in 2003, and the M.Sc. degree (electrical engineering) at the Polytechnic School of the University of São Paulo (EPUSP) in 2006.

From 2002 to 2004 he was a lecturer at Galvão College and Meta Lux, teaching courses related to electrical and electronics systems. He works at Lorenzetti S/A Indústrias Brasileiras Eletrometalúrgicas since 2000, in Research and Development of New Products Department. Since 2005, he is a lecturer (mathematics) at Prefeitura Municipal de São Paulo. Among his areas of interest are: quality of power, electrical heating, as well as their application to electrical power systems.

Paulo Sérgio Valle de Carvalho was born in Sao Paulo, Brazil, in 1963. He received his his B.Sc. degree (electrical engineering) from Mogi das Cruzes University, Mogi das Cruzes, Brazil, in 1992.

He worked at Philips do Brazil from 1987 to 1996 in Research and Development of New Products and Electronic Laboratories Department. He works at Lorenzetti S/A Indústrias Brasileiras Eletrometalúrgicas since 1998 in Research and Development of New Products Department. Among his areas of interest are: quality of power, electrical heating, as well as their application to electrical power systems. 